\title{
PERAN GENERAL STORE SECTION DALAM MENDUKUNG MUTU PELAYANAN USAHA HOTEL
}

Ita Nurjanah ${ }^{1}$, Yuliani Putri ${ }^{2}$, dan Hary Hermawan ${ }^{3}$

${ }^{1,2,3}$ Sekolah Tinggi Pariwisata AMPTA Yogayakarta, Indonesia. Email: hary@ampta.ac.id

\begin{tabular}{|c|}
\hline \hline \\
\hline \\
Histori Artikel \\
Submitted: \\
14 Maret 2018 \\
Reviewed: \\
23 April 2019 \\
Accepted: \\
1 Mei 2019 \\
Published: \\
15 Mei 2019 \\
\hline
\end{tabular}

\begin{abstract}
General Store is one of the important sections in Hotels that are included in accounting Deparment. The general store is a storage place for all operational items of the hotel. Each hotel makes its own eforts to keep the inventory of the hotel which will become the guest necessities. This research aims to know what eforts are made to maintain the quality of hotel operational goods through the role of general store section at The Phoenix Hotel Yogyakarta. Is in accordance with the standard or does not give special treatment to the operational goods (ignored). The research method used is qualitative descriptive method by collecting data through interview. Interviews were conducted with general store staf, cost control staf, and trainee of food beverage at The
\end{abstract}

Phoenix Hotel Yogyakarta. The results of the research show that The Hotel Phoenix Yogyakarta made positive eforts that can reduce damage to goods stored in the general store and always ensure the goods that come to the guests in good condition, so that guests will feel satisfied.

Keywords : General store, quality assurance, guest satisfaction

\section{PENDAHULUAN}

Pariwisata telah terbukti mampu menjadi solusi dalam menopang ekonomi Negara Indonesia. Banyak industri pariwisata di berbagai daerah telah terbukti mampu menciptakan lapangan kerja, menciptakan peluang usaha baru, meningkatkan pendapatan daerah dan kesejahteraan sosialekonomi pada umumnya (Hermawan, 2016a; dan Hermawan, 2016b)

Trend dalam ekonomi global saat ini, usaha jasa mendominasi ekonomi global. Usaha jasa terbukti mampu berkontribusi menyumbang Gross Domestik Bruto (GDP) global terbesar. Industri jasa termasuk pariwisata dan hospitality industry menyumbang sebesar 64\% GDP Global, diikuti industri manufaktur $32 \%$, kemudian sisanya sebanyak $4 \%$ disumbang industri pertanian/ agriculture (Lovelock, 2011).
Dalam upaya mengembangkan dunia kepariwisataan, sektor usaha hospitality seperti hotel merupakan unsur pendukung pariwisata yang sangat penting. Saat ini, hotel telah berkembang menjadi usaha yang handal yang menjadi salah satu penopang utama dalam pembangunan pariwisata. Hotel juga merupakan usaha padat karya yang mampu menyerap banyak tenaga kerja.

Dalam operasionalnya yang padat karya, hotel memiliki departemen yang banyak. Namun, jumlah departemen yang ada di hotel satu dengan hotel lainnya berbeda. Hal ini tergantung besar kecilnya skala usaha hotel. Semakin besar suatu hotel semakin banyak departemen yang ada. Semakin banyak departemen, semakin mudah dalam operasional hotel, karena pembagian tugas yang lebih khusus dan terfokus dengan bagiannya. Salah satu departemen yang sangat penting dalam menunjang operasional 
hotel adalah departemen akunting (keuangan), dalam hotel lebih umum disebut sebagai accounting departement.

Accounting departement bertanggung jawab atas kelancaran serta pengendalian system administrasi keuangan hotel termasuk segala pengeluaran dan pemasukan keuangan. Dalam accounting departement terdapat beberapa section salah satunya yaitu general store.

Secara umum tugas general store adalah menjaga, memelihara persediaan barang kebutuhan tamu. Seluruh barang supplies maupun material lainnya disimpan dalam general store. General store merupakan salah satu section penting yang ada di hotel. Semua kegiatan hotel memerlukan supplies/ material setiap hari, khususnya food \& beverage deparment dan housekeeping (Bagyono, 2007). Oleh karena itu, artikel ini mencoba mendiskusikan secara detail sejauh mana peran gereral store section dalam menjamin kelancaran operasional hospitality berdasarkan studi yang telah dilakukan sebelumnya di The Poenix Hotel Yogyakarta.

\section{LITERATURE REVIEW Usaha Hospitality}

Dari beberapa litaratur keilmuan maupun asal kosa katanya, diperoleh difinisi hospitality dalam berbagai pemahaman yang memiliki sedikit perbedaan. Diantara berbagai pengertian yang ada adalah sebagai berikut :

Secara etimologi, kata hospitality berasal dari bahasa Proto-Italic (merupakan cikal bakal bahasa latin) "hospes". Kata "hospes" tersebut merupakan gabungan kata "hostis" yang berarti orang asing, dan "postis" yang berarti tuan rumah. Hospitality dalam bahasa Latin disebut "hospitum" (atau kata sifatnya hospitalis), yang berasal dari hospes, yang artinya tamu atau tuan rumah. Konsep ini juga dipengaruhi oleh kata Yunani "xenos" $f$ yang menunjuk kepada orang asing yang menerima sambutan atau yang melakukan penyambutan terhadap orang lain (Hershberger, 1999). Hospitality dalam pengertian nomor 1 dan 2 diatas dimaknai dalam dari sudut pandang subjek atau pelaku, kata "hospes" yang berarti tamu.

Hospitality berarti sikap sebagai tuan rumah yang baik. Sering diartikan sebagai keramahtamahan orang yang suka menjamu, akrab dan dapat menciptakan suasana santai (Nouwen, 1998). Hospitality dalam pengertian ini dimaknai sebagai bentuk kata kerja (Hermawan et al, 2018).

Sedangkan dalam bahasa Inggris hospilality didifnisikan sebagai kata friendly yang artinya "ramah" yang murah hati atau dermawan dan memberikan hiburan kepada tamu atau orang baru. Kadang-kadang sering digunakan untuk memberikan perlakuan istimewa terhadap tamu yang tinggal dan menggunakan fasilitas. Adapun industry hospitality dapat diartikan sebagai bentuk perusahaan yang terlibat dalam penyediaan jasa untuk tamu (Concierge Oxford Dictionary). Hospitality dalam Kamus Inggris-Indonesia, memiliki makna keramahtamahan, kesukaan/kesediaan menerima tamu (Echols,1976).

Hospitality merupakan interaksi yang terjadi antara tuan rumah dengan tamu pada saat yang bersamaan mengkonsumsi makanan dan minuman serta akomodasi (Webster, 2000). Hospitality juga dapat dimaknai sebagai sikap keramah-tamahan dalam artian merujuk pada hubungan antara tamu (guset) dan tuan rumah atau penyedia jasa (host) dan juga merujuk pada aktivitas keramahtamahan yaitu : penerimaan tamu, dan pelayanan untuk para tamu dengan kebebasan dan kenyamanan.

Menurut Mill (1990) : “The hospitality of an area is the general feeling of welcome that tourists receive while visiting the area. People do not want to go where they do not feel welcome." Jika diartikan secara bebas, hospitality adalah tempat dimana wisatawan 
dapat merasa diterima ketika mengunjungi tempat itu. Orang-orang tidak akan datang jika mereka merasa tidak diterima (Hermawan et al., 2018).

Hospitality memiliki arti keramah-tamahan, kesopanan, keakraban dan juga rasa saling menghormati. Jika dikaitkan dengan industry pariwisata, dapat diibaratkan bahwa hospitality merupakan roh, jiwa, semangat dari pariwisata. Tanpa adanya hospitality dalam pariwisata, maka seluruh produk yang ditawarkan dalam pariwisata itu sendiri seperti benda mati yang tidak memiliki nilai untuk dijual.

Hospitality bukan hanya soal keramahtamahan seperti dalam arti sempit bahasa (hospitable). Namun hospitality yang merupakan pengetahuan dan seni yang kompleks dalam menjual jasa, yaitu jasa dengan pelayanan yang penuh rasa hormat dan penuh rasa kemanusiaan sesuai kebutuhan jiwa manusia yang ingin dihormati dan dihargai sebagai manusia seutuhnya yang memiliki akal dan budi (Hermawan et al., 2018).

Bisnis hospitality bukan hanya tentang menjual kamar-kamar hotel kelas elit, ataupun menjual makanan-makanan enak untuk sekedar memenuhi kebutuhan perut. Akan tetapi bisnis hospitality adalah bisnis yang membutuhkan jiwa atau ruh dalam sendi-sendi operasionalnya. Hospitality adalah mengenai bagaimana menciptakan produk mati menjadi hidup, sehingga langsung dapat menyentuh perasaan pelanggan sebagai manusia yang juga memiliki jiwa (Hermawan et al., 2018).

Usaha hospitality sebagai usaha jasa (pelayanan) memiliki karakter yang lebih spesifk dalam operasionalnya. Menurut beberapa ahli setidaknya hospitality memiliki 7 karakteristik khusus yang sedikit berbeda jika dibandingkan bentuk usaha jasa lain.

Intangibility, merupakan segala hal yang dapat memberikan rasa kehangatan kepada tamu sebagai manusia, serta kesediaan untuk menyenangkan hati orang lain (Sulastiyono, 2008). Intangibility juga didefnisikan sebagai variabel produk yang tidak nyata, atau sesuatu yang susah diterjemahkan menggunakan panca indera (pengecap, indera melihat, pendengar, dan indera peraba), akan tetapi masih dapat dirasakan dan dialami oleh jiwa manusia melalui akal dan perasaan, yang menentukan kepuasan (Hermawan et al., 2018).

Simultan berarti proses produksi dan konsumsi terjadi pada saat yang bersamaan. Pengertian lainya adalah dari Robert G. Murdick dkk (1990) dalam Hermawan dkk (2018) menyatakan bahwa pelayanan dapat berbentuk barang dan jasa, pada umumnya dikonsumsi dan diproduksi secara bersamaan.

Dalam usaha jasa, pelanggan merupakan input. Jasa atau pelayanan yang disediakan oleh penyedia jasa tidak dapat dilaksanakan tanpa kehadiran pelanggan sebagai input pelayanan tersebut (Ariani, 2009).

Secara lebih tegas, produk hospitality hanya dapat diproduksi pada saat bersamaan dengan waktu konsumsi pelanggan, "Proses melayani hanya akan terjadi jika sudah ada yang akan dilayani", dalam hal ini waktu konsumen menikmati produk jasa juga berpartisipasi dalam proses pembuatan (Hermawan et al., 2018).

Heterogeneity, Yoeti (2004) mengatakan bahwa "Jasa tidak memiliki standar ukuran yang objektif." Variable yang menentukan puas dan tidak puas dari masing-masing konsumen juga akan sangat beragam, sangat relatif, serta sangat subyektif, walaupun terhadap satu produk hospitality yang sama (Hermawan et al., 2018).

Zeithaml dan Bitner (1996) mengatakan bahwa dampak dari karakter produk hospitality yang heterogen menjadikan produk hospitality akan sangat tergantung pada kinerja masing masing staf dalam memberikan pelayanan. 
Perisability, mengandung arti bahwa produk hospitality tidak dapat disimpan (Lovelock, 2011). Juga dapat berarti bahwa produk hospitality tersebut tidak bertahan lama (Hermawan et al., 2018).

Tangible atau "komponen produk nyata" adalah segala sesuatu yang dapat dilihat, disentuh/diraba, diukur dan dihitung (Sulastiyono, 2011).

Secara umum komponen produk nyata ini termasuk tempat, desain furniture, seragam karyawan, fasilitas-fasilitas, serta berbagai aspek nyata lain yang memperngaruhi kepuasan pelanggan.

Immovability, Karakteristik produk hospitality selanjutnya adalah immovable yang memiliki arti tidak dapat dipindahkan (Hermawan et al.,2018). Artinya bahwa produk hospitality hanya dapat dinikmati atau dikonsumsi di tempat dimana produk hospitality itu dibuat.

Inseparability, Philip Kotler (dalam Yoeti, 2004) dan Lovelok (2011) memberi batasan service, sebagai suatu aktivitas yang memberikan manfaat yang ditawarkan oleh satu pihak kepada pihak lain dalam bentuk tidak nyata (intangible) dan tidak menimbulkan perpindahan kepemilikan (Inseparability).

Dalam bisnis hospitality, pengalaman, kebanggaan dan naiknya nilai diri akibat manfaat produk hospitality, merupakan sesuatu yang dibeli (Lovelock, 2011).

\section{Pelayanan Hospitality}

Yoeti (2004) mendefnisikan jasa (service) sebagai suatu produk yang tidak nyata (intangible) dari hasil kegiatan timbal balik antara pemberi jasa (producer) dan penerima jasa (consumer) melalui suatu atau beberapa aktiftas untuk memenuhi kebutuhan pelanggan.

Kotler \& Makens (1999) memberi batasan tentang pelayanan/ service sebagai suatu aktivitas yang memberikan manfaat, yang ditawarkan oleh satu pihak kepada pihak lain dalam bentuk tidak nyata (intangible) dan tidak menimbulkan perpindahan kepemilikan Zeithaml dan Bitner (1996) memberi batasan tentang pelayanan/ service sebagai berikut :

"Service is include all economic activities whose output is not a physical product or contraction is generally consumed at that time it is produced and provides added value in forms (such as conveniencef amusementf confort or health".

Jika diartikan secara bebas, pelayanan memiliki makna sebagai bentuk aktiftas ekonomi yang hasilnya bukan merupakan produk dalam bentuk fsik, atau berupa kontruksi atau barang, yang biasa dikonsumsi pada saat yang bersamaan dengan waktu produksi sambil memberikan nilai tambah misalnya kenyamanan, hiburan, kesenangan, atau kesehatan.

Menurut teori beberapa ahli pelanggan menilai kualitas pelayanan hospitality melalui dimensi-dimensi pelayanan sebagai tolok ukur.

Reliabilitas (realibility), adalah kemampuan untuk memberikan secara tepat dan benar jenis pelayanan sesuai yang telah dijanjikan kepada pelanggan.

Responsif (Responsiveness), yaitu kesadaran atau keinginan untuk bertindak capat dalam membantu pelanggan dan memberikan pelayanan tepat waktu.

Kepastian atau jaminan (Assurance), adalah pengetahuan dan kesopan santunan serta kepercayaan diri pegawai. Dimensi assurance memiliki ciri-ciri: kompetensi untuk memberikan pelayanan dan memiliki sifat respek kepada tamu.

Empati (Empathy), memberikan perhatian individu kepada tamu secara khusus. Dimensi empati memiliki ciri-ciri : kemauan untuk melakukan pendekatan, memberikan perlindungan dan usaha untuk mengerti keinginan, kebutuhan dan perasaan tamu.

Kemampuan akses (Access) kemampuan pendekatan dan kontak mata 
Kesopanan, rasa hormat, pertimbangan dan keramahan personil kontak pelanggan

Communication, menjaga informasi dalam bahasa mereka dapat memahami

8.Keamanan, kebebasan dari risiko, bahaya atau diragukan

Memahami pelanggan membuat upaya untuk mengetahui kebutuhan pelanggan.

Nyata (Tangibles) yaitu sesuatu yang Nampak atau yang nyata yaitu: penampilan para pegawai yang rapi, fasilitas peralatan yang bersih dan higyene, peralatan fasilitas penunjang yang berfungsi baik dan lain sebagainya (Parasuraman dkk., dalam Saleh \& Ryan, 1991; dan Zeithaml \& Bitner, 1996).

\section{Mutu}

Kecocokan pengunaan suatu produk adalah apabila produk mempunyai daya tahan lama, produk yang digunakan akan meningkatkan citra atau status konsumen yang digunakan akan meningkatkan citra atau status konsumen yang memakainya, produk tidak gampang rusak, adanya jaminan kualitas kepada pelanggan yang ramah tamah, jujur, yang dapat menyenangkan atau memuaskan pelanggan (Juran, 1993).

Prawiro Sentono dalam Ulfah dan Raharjo (2007) mengatakan bahwa produk berkualitas prima lebih atraktif bagi konsumen, bahkan dapat meningkatkan volume penjualan. Tetapi lebih dari itu, produk berkualitas mempunyai aspek penting lain.

Konsumen yang membeli produk berdasarkan mutu, umumnya mereka mempunyai loyalitas produk yang besar dibandingkan dengan konsumen yang membeli berdasarkan orientasi harga. Normalnya, konsumen berbasis mutu akan selalu membeli produk tersebut sampai saat produk tersebut membuat dia merasa tidak puas karena adanya produk lain yang lebih bermutu. Tetapi selama produk semula masih selalu melakukan perbaikan mutu (quality improvement) dia akan tetap setia dengan tetap membelinya. Berbeda dengan konsumen berbasis harga, dia akan mencari produk yang harganya lebih murah, apapun mereknya. Jadi konsumen terakhir tersebut tidak mempunyai loyalitas produk.

Bersifat kontradiktif dengan cara berfkir bisnis tradisional, ternyata bahw a memproduksi barang bermutu tidak secara otomatis lebih mahal dengan memproduksi barang bermutu rendah. Banyak perusahaan menemukan (discovery) bahwa memproduksi produk bermutu tidak harus berharga lebih mahal. Mengapa? Fakta menunjukkan, bahwa cara berproduksi untuk menghasilkan produk bermutu tinggi secara simultan meningkatkan produktivitas, antara lain mengurangi penggunaan bahan dan mengurangi biaya (Inggrawan, 2010).

Misalnya, diberikan contoh dua ibu rumah tangga masing masing mendapat pesanan membuat kue donat 5000 buah yang harus diserahkan besok pagi pukul 10.00. Keduanya ahli membuat kue. Bedanya yang satu memakai mixer tradisional (dikocok dengan manual) sedangkan yang satu menggunakan mixer listrik. Juga ovennya, yang satu dengan oven tradisional, sedangkan yang lain dengan oven listrik. Soal kecepatan, artinya produktivitas per satuan waktu tentunya, alat modern (yang harganya lebih mahal) akan lebih cepat berproses produksi. Hasilnya, produk akan lebih bermutu, harga jualpun mungkin lebih murah (competitive), karena tidak perlu mengeluarkan upah tenaga kerja yang lebih banyak (baik untuk mengaduk adonan) maupun untuk "menjaga" oven yang otomatis.

Sebaliknya, menjual barang tidak bermutu kemungkinan akan banyak menerima keluhan dan pengembalian barang dari konsumen. Atau, biaya untuk memperbaikinya sertqa after sales services menjadi sangat besar, selain memperoleh 
citra tidak baik. Termasuk potensi kecelakaan yang diderita oleh konsumen akibat pemakaian produk yang bermutu rendah. Konsumen tersebut mungkin akan menuntut ganti rugi melalui pengadilan

\section{Kepuasan Pelanggan}

Kepuasan adalah tingkat perasaan seseorang setelah membandingkan kinerja atau hasil yang dirasakan dibandingkan dengan harapannya (Kotler dan Makens, 1999). Dalam bukunya yang lain, Kotler (2002) mendefnisikan kepuasan sebagai perasaan senang atau kecewa seseorang yang muncul setelah membandingkan antara persepsi/ kesannya terhadap kinerja (atau hasil) suatu produk dan harapan-harapannya. Kepuasan tentang produkdibandingkan dengan harapan wisatawan sebelum menikmati produk hospitality dan pariwisata.

Kepuasan telah begitu lama menjadi perhatian para ahli pemasaran, karena wisatawan yang puas akan cenderung loyal terhadap suatu produk atau jasa.

Kepuasan pelanggan merupakan faktor penentu, apakah suatu bisnis akan berkelanjutan atau tidak (Hermawan, 2017a). Begitu juga dalam usaha hospitality dan pariwisata, upaya untuk menciptakan kepuasan wisatawan juga menjadi perhatian serius para pengelola usaha.

\section{METODE}

Artikel ini ditujukan untuk menggali lebih dalam tentang peran gereral store section dalam menjamin kepuasan pelanggan di The Phoenix Hotel Yogyakarta. Metode penelitian yang digunakan merupakan metode desktiptif kualitatif. Selain itu pendekatan kualitatif digunakan untuk memperoeh gambaran diskriptif yang lebih luas mengenai fenomena yang diamati (Moleong, 2004). Karena, pendekatan kualitatif dipandang mampu menggali pemaknaan terhadap fenomena secara lebih mendalam (Creswell, 1994).
Lokasi penelitian di The Phoenix Hotel Yogyakarta Sedangkan waktu pelaksanaanya telah dilakukan pada Bulan Maret 2018 (2021 Maret).

Sebagai jaminan kevalidan data, dilakukan kroscek menggunakan 3 sumber data, biasa dikenal sebagai triangulasi (Hermawan, 2017b).

Responden yang menjadi narasumber utama adalah Ibu Hari Astuti selaku Staf General Store The Phoenix Hotel Jogja, juga 2 mahasiswa Training bagian Cost Control atas nama Septi, dan Mahasiswa Training bagian Food \& Beverage atas nama Agastya. Teknik pecarian data digunakan adalah wawancara, pengamatan, serta kegiatan dokumentasi berupa pencatatan, perekaman, video, dan foto-foto.

Analisis data digunakan mengacu pada kaidah-kaidah metodologi kualitatif secara umum seperti reduksi, penyajian data, verifkasi serta triangulasi data (Moleong, 2004; dan Brahmanto, Hermawan, \& Hamzah, 2017)

\section{HASIL DAN PEMBAHASAN}

Data berikut merupakan hasil wawancara dengan Ibu Hari Asturi selaku Staf bagian General Store, terkait dengan tugas dan tanggung jawab Ibu Hari Asturi selaku Staf bagian general store untuk menjamin barang yang ada bisa dalam keadaan baik. Berikut yang dilakukan Ibu Hari Asturi selaku staf bagian general store.

Mengusahakan stok selalu terjaga untuk kenyamanan tamu. Untuk meningkatkan penjualan staf di general store perlu mengusahakan stok barang kebutuhan hotel. Setiap hari ada saja barang yang yang datang dari konsumen, ada barang yang disimpan di general store kemudian di pakai untuk operasional saat itu juga, atau ada barang yang disimpan beberapa hari bahkan minggu/bulan di Store (barang ini misalnya barang yang kering seperti material) . Barang 
yang ada di general storebermacam- macam. Mulai dari Beverage (alcohol dan soft drink), Guest Supplies, Guest Amenities, Paper \& Printing \& Food

Meneliti barang yang baru saja datang. General store dan Receiving akan meneliti barang yang baru datang dari supplier, apakah barang itu rusak/baik. Barang yang rusak akan dikembalikan kepada supplier sedangkan barang yang baik akan diterima Receiving kemudian disimpan di General Store.

Penyimpanan barang di general store. Perlakuan penyimpanan barang di general store setiap barang berbeda-beda. Barang seperti alcohol beverage, dairy product akan disimpan dalam chiller. Hal ini dapat mengurangi kerusakan pada barang tersebut.

Penulisan bin card. Bin card adalah form khusus yang berisi nama item, jumlah dan tanggal masuk/ keluar barang. Dari bin Card ini bisa terlihat barang yang tersedia. Setiap pengambilan barang maka jumlah dalam Bin Card akan dikurangi. Sebaliknya jika ada barang masuk dari Supplier melalui Receiving, makan Bin Card akan ditambah. Menerapkan metode FIFO (First In First Out)

First In First Out merupakan metode pengambilan barang dengan melihat masa kadaluarsa barang. Barang yang memiliki masa kadaluarsa pendek diletakkan paling luar yang kemudian akan diambil terlebih dahulu untuk operasional. Sebaliknya barang yang baru datang dari supplier yang memiliki masa kadaluarsa lama ditaruh paling dalam.

Yang dilakukan Staf /Trainee Food And Beverage saat megambil barang: (1) Menyerahkan store requesition form kepada staf general store store requisition. Form berisi daftar barang yang akan diambil di Store. Setiap departemen wajib menggunakan form ini untuk memudahkan system yang ada; (2) Staf food \& beverage mengambil barang. Saat pengampilan barang, staf harus menggunakan metode FIFO, mengambil barang paling luar yang mempunai masa kadaluarsa lebih pendek dibanding barang yang di bawahnya/didalamnya; (3) Staf food \& beverage di temani oleh cost control untuk mengecek barang yang diambil. Mulai dari cacat atau tidaknya barang, masa kadaluarsa atau expired juga jumlah barang yang diambil sesuai dengan store requesition form. Sedangkan hal yang dilakukan cost control : (1) Cost control akan mengawasi seluruh perputaran barang yang ada di general store, apakah barang tersedia sesuai dengan yang tersedia di system; (2) Cost control bertugas menghitung barang yang terjual kemudian akan mengambil barang sesuai dengan yang terjual. Misalnya, pada tanggal 1 maret 2018 hotel laku menjual soft drink X sebanyak 10, maka hari itu juga persediaan Food \& Beverage harus ditambah 10, kemudian staf Food \& Beverage akan mengambil 10 kaleng soft drink tersebut; (3) Cost control mengecek barang rusak atau cacat dan masa kadaluarsa. Barang yang cacat seharusnya tidak digunakan saat operasional.

Memprioritaskan tamu merupakan hal penting dalam penyelenggaraan usaha hotel (hospitality lain). Oleh sebab itu, perlunya manajemen hotel mengolah dan mengemas produk atau jasa secara maksimal agar tercipta kepuasaan pelanggan, sehingga pelanggan akan betah dan memilih untuk kembali menginap di hotel tersebut.

Prioritas yang dilakukan yaitu pada kualitas barang atau produk. Barang produk tersebut nantinya adalah konsumsi tamu. Barang yang dijual kepada tamu merupakan barang pilihan berkualitas yang disediakan hotel. Barang yang berkualitas bisa didapatkan atas kerja sama pihak hotel dengan supplier.

General store merupakan section penting dalam pemeliharaan barang, agar barang yang berkualitas dapat digunakan tamu, sehingga tamu bisa merasa puas. Upaya yang di lakukan general store seperti metode FIFO, Penulisan bin card \& pemeliharaan setiap barang, dapat meningkatkan mutu 
pada suatu barang. Barang yang kondisinya baik sampai kepada tamu, maka tamu akan merasa senang, sepadan dengan jumlah biaya tamu menginap. Sebaliknya, jika suatu barang itu cacat dan nantinya sampai ke tamu, maka tamu akan mempertanyakan atau tamu dapat memiliki kesan tidak baik terhadap hotel yang nantinya reputasi hotel menjadi jelek.

Barang-barang basah seperti sayuran yang baru datang biasanya di cuci sebelum nantinya masuk di commisary. Daging dan ikan yang sudah bersih nantinya juga masuk dalam ruangan butcher, dengan suhu tertentu, tergantung jenis nya. Minuman beralkohol juga disimpan dalam ruangan khusus yang dingin. Semua barang di The Hotel Phoenix Yogyakarta di pelihara baik sesuai standard pemeliharaan barang di store.

Penempatan barang berbeda-beda tergantung perlakuannya. Ini bertujuan untuk mengurangi resiko kerusakan barang. Metode $F I F O$, penggunaan bin card juga membantu barang tetap tersedia dalam keadaan baik.

The Hotel Phoenix merupakan hotel yang sudah melakukan penerapan/perlakuan baik dengan barang yang akan menjadi barang konsumsi tamu. General store dengan bantuan cost control melakukan pengawasan barang yang ada di hotel. Pengawasan barang ini bertujuan untuk mengetahui kondisi barang dan ketersediaannya, yang akan di konsumsi nantinya oleh tamu.

\section{KESIMPULAN}

Prioritas tamu merupakan hal penting dalam penyelenggaraan usaha hospitality khususnya usaha jasa perhotelan. Manajemen hotel perlu mengolah dan mengemas produk jasa secara maksimal agar tercipta kepuasaan pelanggan sehingga pelanggan akan betah dan memilih untuk kembali menginap di hotel tersebut.

Sektor produksi adalah salah satu bagian yang ada dalam perusahaan yang memerlukan adanya suatu pengendalain mutu. Pengendalian ini dilaksanakan untuk menjamin agar mutu produksi selalu sesuai dengan standar yang telah ditetapkan perusahaan.

The Hotel Phoenix Yogyakarta sebagai hotel bintang lima $(* * * * *)$ sudah memiliki upaya standard penyimpanan barang di general store agar barang selalu dalam kondisi baik, misalnya : (1) Penerapan system FIFO; (2) $P$ enulisan bin card yang dilakukan dengan tertib; (3) Pemeliharaan barang sesuai kondisi barang; dan (4) Mengusahakan stok selalu terjaga untuk dapat memenuhi permintaan tamu sehingga kenyamanan dan kepuasan tamu selalu terjaga.

Upaya yang dapat dilakukan hotel untuk menjamin kepuasan pelanggan tidak lain adalah dengan selalu menjaga standar mutu produk jasa atau barang. Dengan mutu produk jasa atau barang yang berkualitas maka tamu akan selalu merasa puas. Diharapkan dengan tamu yang puas akan menceritakan kabar baik tersebut kepada orang lain yang nantinya akan berdampak pada reputasi hotel, dalam bahasa pemasaran adalah word of mouth. Dengan adanya tamu yang loyal, diharapkan pendapatan hotel pun akan meningkat karena banyaknya tamu yang menginap.

\section{REFERENSI}

Ariani, D. W. 2009. Manajemen Operasi Jasa. Yogyakarta: Graha Ilmu.

Begyono. 2007. Pariwisata Perhotelan. Bandung: Alfabeta.

Creswell, J. W. 1994. Research DesignQualitativef Quantitativef and Mixed Method. London: SAGE Publications.

Echols, J. M. 1976. An English-Indonesian dictionary. Cornell University Press PT Gramedia. 
Hermawan, H. 2017. Pengaruh Daya Tarik

Wisata, Keselamatan dan Sarana

Wisata Terhadap Kepuasan serta

Dampaknya terhadap Loyalitas

Wisatawan : Studi Community Based

Tourism di Gunung Api Purba

Nglanggeran. Wahana Informasi

Pariwisata : Media Wisata, 15(1), 562-

577.

. 2017. Pengembangan Destinasi

Wisata pada Tingkat Tapak Lahan dengan Pendekatan Analisis SWOT.

Jurnal Pariwisata, 4(2), 64-74.

Hermawan, H., Brahmanto, E., \& Hamzah,

F. 2018. Pengantar Manajemen

Hospitality. Jawa Tengah: PT Nasya

Expanding Management.

Hershberger, M. 1999. A Christian view of hospitality: Expecting surprises. Herald Press.

Inggrawan, A. Y. 2010. Studi tentang Citra Perusahaan Melalui Kredibilitas Perusahaan pada PT BNI (Persero) Tbk di Semarang. Jurnal Sains Pemasaran Indonesia, 9(1), 32-44.

Juran, J. M. 1993. Mode in USA : A Renoissonce in Quality. Harvard Business Review.

Kotler, P. 2002. Manajemen Pemasaranf terjemahan Hendra Teguhf edisi Milleniumf cetakan pertama (1st ed.). Jakarta: Prenhalindo.

Kotler, P., \& Makens, J. C. 1999. Marketing for Hospitality and Tourism 5/e. Pearson Education India.

Lovelock, C. 2011. Services Marketing 7/e. Pearson Education India.
Mill, R. C. 1990. Tourism: the international business. Prentice-Hall International, Inc.

Moleong, L. 2004. Metode Penelitian Kualitatif. Bandung: Remaja RosdaKarya.

Nouwen, H. J. M. 1998. Reaching Out: A Special Edition of the Spiritual Classic Including Eeyond the Mirror. Zondervan.

Saleh, F., \& Ryan, C. 1991. Analysing service quality in the hospitality industry using the SERVQUAL model. Service Industries Journal, 11(3), 324345.

Sulastiyono, A. 2008. Manajemen Penyelenggaraan Hotel: Seri Manajemen Usaha Jasa Sarana Pariwisata dan Akomodasi. Bandung: Alfabeta.

Webster, K. 2000. Environmental Management in the Hospitality Industry: A Guide for Students and Managers. Cengage Learning EMEA.

Yoeti, O. A. 2004. Strategi Pemasaran Hotel. Jakarta: Gramedia Pustaka

Ulfah, F., \& Rahardjo, S. T. 2013. Analisis Pengaruh Implementasi Manajemen Kualitas terhadap Kinerja Organisasi pada Usaha Kecil Menengah (UKM) di Kota Salatiga (Doctoral dissertation, Fakultas Ekonomika dan Bisnis).

Utama. Zeithaml, V. A., \& Bitner, M. J. 1996. Services Marketing. New York: Mc Graw Hill. 